\title{
Biosurfactant applied to remediation of cadmium contaminated soil
}

\author{
Da Zhao ${ }^{1, a}$, Tong Bao ${ }^{1, b}$ \\ ${ }^{1}$ Key Laboratory of Regional Environment and Eco-Remediation, Shenyang University, Shenyang \\ 110044, China. \\ azhaoda81@126.com, bbaotong801231@aliyun.com.cn
}

Keywords: biosurfactant; soil remediation; cadmium;

\begin{abstract}
This study reported the feasibility of flushing remediation of cadmium contaminated soil using bacteria fermentation solution. Batch experiments were performed to test the factors influencing remediation of cadmium contaminated soil. The effects of concentration, $\mathrm{pH}$ value and contact time on the removal capacities of cadmium by fermentation solution had been studied. The results showed that the fermentation solution was effective for removal of cadmium from the contaminated soil. The results showed that the removal efficiency of cadmium increased with the increase of fermentation solution concentration. The fermentation solution showed a better removal efficiency of cadmium in alkaline conditions, getting the highest removal efficiency of $75.3 \%$. In addition, with the increase of washing time, higher removal efficiency was obtained.
\end{abstract}

\section{Introduction}

Background soil trace element levels are typically below the threshold for adverse health and environmental effects. However, elevated concentrations arise from mining, burning of fossil fuels, smelting, industrial activities, agricultural operations and waste disposal practices ${ }^{[1]}$. Because heavy metals in the environment are posing significant threats to human health and ecological environment, therefore reliable remediation techniques are required for site clean-up ${ }^{\text {[2] }}$. Removal of contaminants is the most permanent solution to the environmental problem, metals can be removed by physical methods or chemical methods involving the application of appropriate leaching solutions to the contaminated soil ${ }^{[3]}$. Soil washing is a water-based process employing physical separation and chemical extraction to remove contaminants from soil. Microorganism fermented to produce biosurfactant, and it is better than synthetic washing liquid on environmental friendly. This reseach is a contribution to the problem of cadmium removal and then it gives its characteristics to finally show adsorption capacity with respect to cadmium in contaminated soil.

\section{Materials and methods}

\section{Reagents and instruments}

The strain with high surface activity is isolated from the samples of vineyard soil in Liaoning. Through primary identification the strain belong to Pseudonomas. Fermentation medium(g/L): yeast extract 0.1, glucose 2, $\mathrm{KH}_{2} \mathrm{PO}_{4} 1, \mathrm{NH}_{4} \mathrm{NO}_{3} 0.5, \mathrm{MgSO}_{4} 0.02, \mathrm{Na}_{2} \mathrm{HPO}_{4} 1$. Put fermented liquid at $8000 \mathrm{r} / \mathrm{min}$ centrifuge with 20 minutes, get rid of the bacteria.

Measurement of heavy metal ions in liquid solutions was performed by AA 220 atomic absorption spectrophotometer (Varian, UAS). A Horiba D-14 pH meter (Kyoto, Japan) was used for solution $\mathrm{pH}$ measurement.

\section{Soil sample}

The soil used in this study was collected from surface soil specimen $(0-20 \mathrm{~cm})$ of the national field research station of Shenyang agroecosystems. Soils were crushed and air-dried to pass through a sieve of $2 \mathrm{~mm}$ openings. Stock soil of cadmium $(20 \mathrm{mg} / \mathrm{kg})$ was prepared by appending cadmium chloride into soil sample to obtain the desired $\mathrm{Cd}^{2+}$ concentration. For analysis of the total concentrations of soil cadmium, soil specimens were digested by $\mathrm{HClO}_{4}-\mathrm{HNO}_{3}-\mathrm{HF}$ mixture in Teflon tubes. The solution of the digested samples was analyzed by atomic absorption 
spectrophotometer.

\section{Batch adsorption experiment}

A series of batch adsorption experiments were executed with bacteria fermentation solution as an extractant to test the effects of concentration, $\mathrm{pH}$ value and contact time on cadmium removals. $1 \mathrm{~g}$ of soil specimen was put into a series of polycarbonate centrifuge tubes, and different volume of fermentation solutions was added to every centrifuge tube. The concentration effects of fermentation solution were adjusted in the range of $5 \%-50 \%$. For $\mathrm{pH}$ value experiment, the different $\mathrm{pH}$ value effects of fermentation solution were researched in the range of 4.0-9.0. The $\mathrm{pH}$ value was adjusted using $1 \mathrm{M} \mathrm{H}_{2} \mathrm{SO}_{4}$ or $1 \mathrm{M} \mathrm{NaOH}$. The suspension liquid were shaken for $24 \mathrm{~h}$ in a $25 \pm 3^{\circ} \mathrm{C}$ thermostat. To find out the effects of contact time on cadmium removals, $1 \mathrm{~g}$ of soil and $10 \mathrm{ml}$ of fermentation solution were put into a series of polycarbonate centrifuge tubes. The $\mathrm{pH}$ value was adjusted to 9.0 using $1 \mathrm{M} \mathrm{H}_{2} \mathrm{SO}_{4}$ or $1 \mathrm{M} \mathrm{NaOH}$. The suspension liquid were shaken for 20min-48h in a $25 \pm 3^{\circ} \mathrm{C}$ thermostat, oscillation frequency set to $250 \mathrm{r} / \mathrm{min}$. Then, the supernatant liquid was poured through a paper filter $(0.45 \mu \mathrm{m}$ particle retention) to remove any floating particles. Batch extractions were executed in triplicates to confirm reproducibility of the results. Filter liquor was analyzed using atomic absorption spectrophotometer to find out the amount of metal left after sorption.

The removal rate (\%) was calculated using the equation.

$$
E \%=\frac{C i-C f}{C i} \cdot 100
$$

where $\mathrm{Ci}$ and $\mathrm{Cf}$ are the concentrations of the metal ion in initial and final solutions, respectively.

\section{Results and discussion}

\section{Effect of Fermentation solution concentration}

The effect of fermentation solution concentration on the removals of cadmium from the soil is shown by plotting concentrations of fermentation solution vs. cadmium removals (Fig.1). The removals of cadmium were found to be dependent on the fermentation solution concentration. The removals of cadmium suddenly increased with the fermentation solution concentration up to 30\%. As the concentration of fermentation solution was further increased from 30\%-50\%, the removal of cadmium from the soil did not increase obviously. Therefore, the optimum fermentation solution concentration is $30 \%$ for soil treatment to avoid introduction of exess fermentation solution into soil. The maximum adsorption capacitiy of cadmium obtained after $24 \mathrm{~h}$ of sorption was $63.4 \%$.

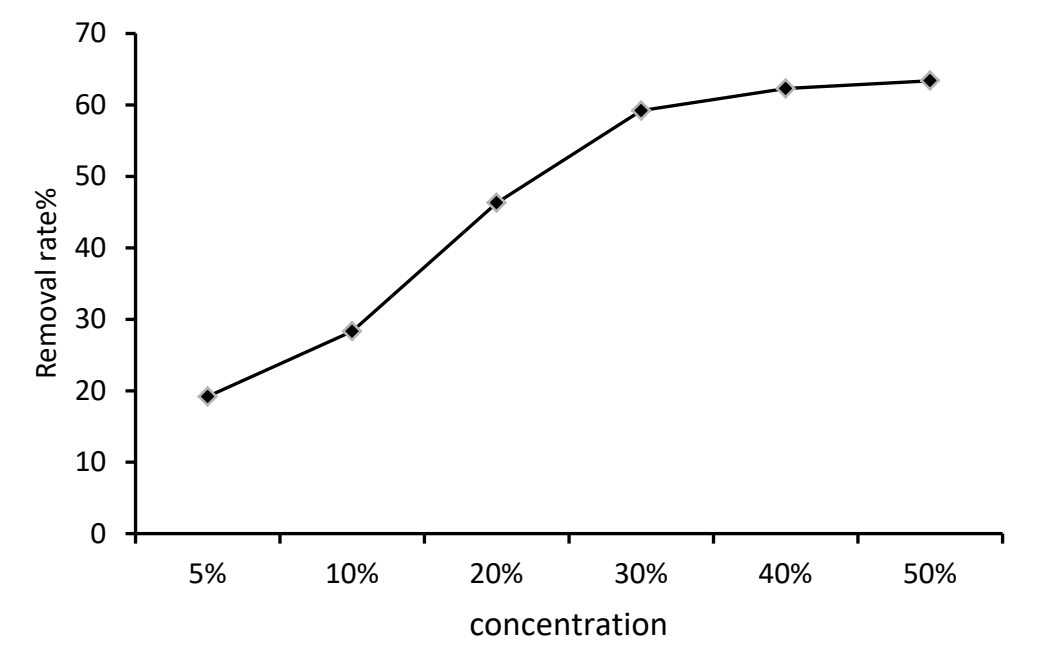

Fig.1 Effect of fermentation solution concentration on the removal of cadmium from the contaminated soil

\section{Effect of fermentation solution $\mathrm{pH}$ value}

The $\mathrm{pH}$ is an important parameter affecting the efficiency of cadmium desorption from the contaminated soil. Effect of fermentation solution $\mathrm{pH}$ on removal of cadmium from the contaminated soil is shown in Fig.2. Results indicated that the removal efficiency of cadmium was 
dependent on fermentation solution $\mathrm{pH}$. The removals of cadmium increased with the fermentation solution $\mathrm{pH}$ up to $4.0-9.0$. Fermentation solution removed $40.0 \%-75.3 \%$ of cadmium at $\mathrm{pH} 4.0-9.0$.

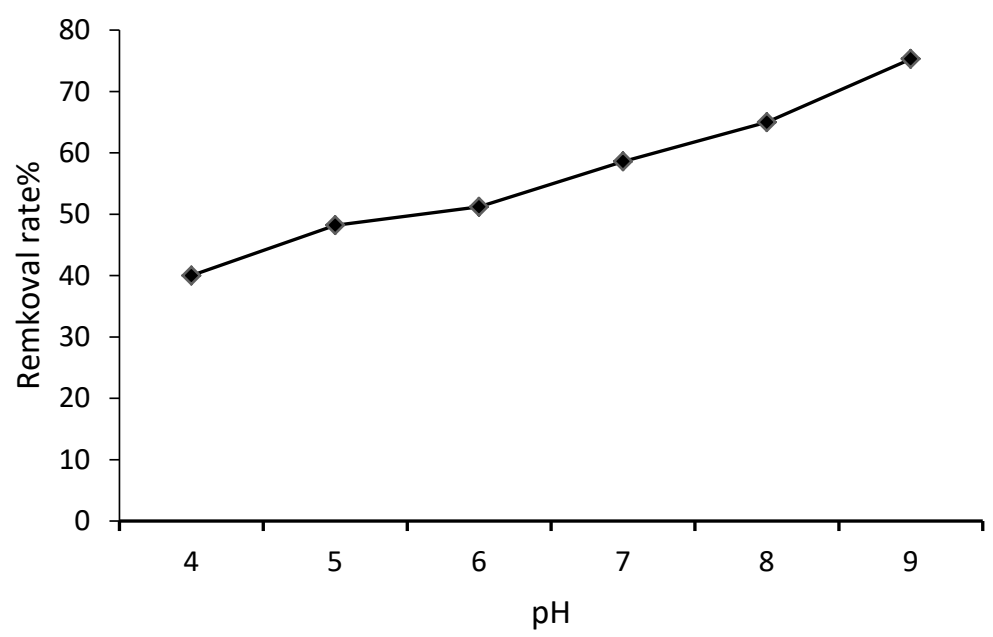

Fig.2 Effect of fermentation solution $\mathrm{pH}$ on removal of cadmium from the contaminated soil

\section{Effect of contact time}

Figs. 3 reveals the effect of contact time on the adsorption of cadmium onto 1:10 solid-liquid ratio. Fermentation solution concentration was 30\%. The $\mathrm{pH}$ for the experiment was 9.0. Result displayed that the adsorption of cadmium increases quickly with time and then reaches equilibrium. It was concluded that $24 \mathrm{~h}$ was sufficient for sorption to attain equilibrium. Fermentation solution removed $73.6 \%$ of cadmium.

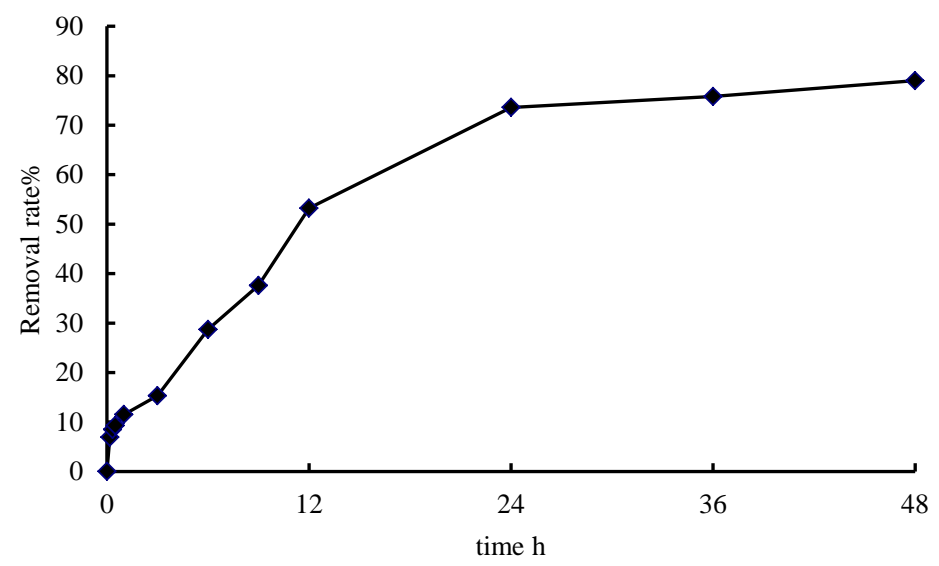

Fig.3 Effect of contact time on removal of cadmium from the contaminated soil

\section{Conclusion}

In conclusion, it turned out that utilization of bacteria fermentation solution was effective for removal of cadmium from the contaminated soil. The following verdicts could be drawn from this research: The optimum fermentation solution concentration was 30\%; The optimum $\mathrm{pH}$ of bacteria fermentation solution was 9.0. The optimum contact time of bacteria fermentation solution was 24h. As a result, bacteria fermentation solution was effective in removing cadmium from the contaminated soil.

\section{Acknowledgement}

We gratefully acknowledged financial supports provided by the general project of Liaoning provincial education department (No.L2015365), scientific research fund of public service industry of agriculture ministry (No.201203035) and project supported by the National Natural Science Foundation of China (41401352). We would like to thank the Laboratory of Eco-Remediation and 
Resorce Reuse, Shenyang University for providing technical and experimental support.

\section{References}

[1] Tejowulan R S, Hendershot W H, Removal of trace metals from contaminated soils using EDTA incorporating resin trapping techniques. J. Enviromental Pollution,1998. 103:135-142.

[2] V.J. Inglezakis, M.D. Loizidou, H.P. Grigoropoulou, “Ion exchange of $\mathrm{Pb}^{2+}, \mathrm{Cu}^{2+}, \mathrm{Fe}^{3+}$, and $\mathrm{Cr}^{3+}$ on natural clinoptilolite: selectivity determination and influence of acidity on metal uptake”, J. Colloid Interface Sci., vol. 26, pp.49-54, 2003.

[3] Abumaizar R, Khan L I, 1996. Laboratory investigation of heavy metal removal by soil washing. J. Journal of the Air and Waste Management Association, 46:765-768.

[4] Asci Y, Nurbas M, Acikel Y S. 2008. A comparative study for the sorption of Cd( II) by soils with different clay contents and mineralogy and the recovery of $\mathrm{Cd}(\mathrm{II})$ using rhamnolipid biosurfactant[J]. Journal of Hazardous Materials, 154(1/3): 663-673

[5] Paria S. 2008. Surfactant-enhanced remediation of organic contaminated soil and water [J]. Advances in Colloid and Interface Science, 138(1) : 24-58

[6] Urum K, Pekdemir T. 2004. Evaluation of biosurfactants for crude oil contaminated soil washing [J]. Chemosphere, 57(9) : 1139-1150

[7] Wang S L, Mulligan C N. 2009. Arsenic mobilization from mine tailings in the presence of a biosurfactant [J]. Applied Geochemistry, 24 (5) :928-935 